\title{
INVESTIGATIONS ON THE EFFECTS OF LOW LASER INFRARED MARKING ENERGY AND BARCODE SIZE ON 2D DATA MATRIX CODE DETECTION ON APPLES
}

\author{
F. Eyahanyo, T. Rath
}

\author{
HighLights \\ - Laser energy, type of marking on the product and product color affected the Data Matrix detection \\ - High laser marking energy resulted in ablation, browning and carbonization \\ - Working direction of the laser beam affected the print growth of the Data Matrix \\ - Proposed algorithm successfully decoded the barcodes on Golden Delicious apples
}

\begin{abstract}
Product marking in horticulture aims at providing robust and permanent means of marking products and preventing theft, tampering and cheating by customers. Direct part marking has sought to provide solutions to these problems. However, unlike in industry where it has been successful, in horticulture there are still a lot of challenges that prevent successful marking and reading of directly marked barcodes on horticultural products. The laser energy, barcode size, product color and days of storage are important factors that affect the marking, quality and readability of directly marked Data Matrix (DM) on apples. Therefore, the objective of this study was to solve the aforementioned problems with these factors by using Synrad 48-5 $\mathrm{CO}_{2}$ laser $(10,600 \mathrm{~nm})$, to mark some apples using low energy levels. Laser energy, the skin of the product and the inertia of the laser beam affected the printing of the DM on the apples. Incomplete marking of the DM at some of the energies used resulted in the DM not being decoded. Generally, there was successful decoding on Golden Delicious compared to Kanzi and Red Jonaprince for 10 days of storage. On the average, the smaller barcode size produced a better detection of the code than the bigger size. The better detection on Golden Delicious can be attributed to the better contrast between the DM and its color. As the days of storage increased, detection decreased for Kanzi and Red Jonaprince. There is a future prospect for directly reading marked apples in real production systems.
\end{abstract}

Keywords. Apple, Apple skin, Barcode size, Data matrix, Laser, Product marking.

$\mathrm{T}$ The need to monitor and trace products through the production, supply, and marketing channels from the manufacturer to the consumer in various commercial applications has increased tremendously in the last decade (Kang and Lee, 2013; Kemény et al., 2014; Tekin, 2014; Ventura et al., 2016). Product marking is valuable for providing information; improving security by preventing theft, tampering with the product and cheating; enhancing the traceability of the product; and acquiring real time information about how the product is faring on the market (Bassoli, 2018). There are various techniques of marking and storing information on products such as adhesive stickers (barcodes, icons, etc.) and Radio Frequency

Submitted for review in January 2020 as manuscript number ITSC 13927; approved for publication as a Research Article by the Information Technology, Sensors, \& Control Systems Community of ASABE in September 2020

The authors are Felix Eyahanyo, PhD, and Thomas Rath, Professor, Biosystems Engineering Laboratory (BLab), University of Applied Sciences, Osnabrueck, Germany. Corresponding author: Felix Eyahanyo, Leibniz University of Hannover, Institute of Horticultural Production Systems, Biosystems Engineering Section, Herrenhäuser Straße 2, 30419 Hannover, Germany; phone: +49 511727804 96; e-mail: eyahanyo@bgt.uni-hannover.de.
Identification (RFID) tags. The former can easily be detached from the product while the later suffers from interference of signals, metal and water (Bassoli, 2018). There is therefore the need to provide permanent, robust and durable alternative methods of marking and identifying products even when exposed to harsh weather conditions throughout the supply chain and full life cycle. Direct Part Marking (DPM) has sought to solve these aforementioned problems. DPM is a permanent way of imprinting information in the form of barcodes, numbers, dates and logos directly on the surface of a product (Wang and Madej, 2014; Denkena et al., 2016; Li et al., 2016; Ventura et al., 2016; He and Joseph, 2017; Bassoli, 2018). Laser marking or etching or branding is the most popular form of DPM. Laser marking provides a high contrast and a permanent mark on the surfaces of the products such as metal, wood, ceramics, and glass (Li et al., 2016; Bassoli, 2018). The need for laser marking that provides a permanent tag on agricultural produce has increased tremendously in recent years due to its profitability and long-term environmental efficiency in energy, plastic, and carbon dioxide emissions (Pullman, 2017). Produce such as vegetables (e.g., onion, tomato, and pepper), fruits (e.g., citrus, avocado, and apple), eggs, flowers, and beaks of chickens have been marked by researchers (table 1). Also, for 
Table 1. Research and applications of laser marking on horticultural/biological products.

\begin{tabular}{|c|c|c|c|c|}
\hline \multicolumn{3}{|c|}{ Parameters } & Products & Literature \\
\hline $\begin{array}{c}\text { Laser } \\
\text { Energy }\end{array}$ & $\begin{array}{l}\text { Laser } \\
\text { Power }\end{array}$ & $\begin{array}{c}\text { Barcode } \\
\text { Size }\end{array}$ & Fruits, Vegetables, Eggs, Wood, etc. & \\
\hline & 0 & 0 & $\begin{array}{l}\text { Lemon, orange } \\
\text { Citrus fruits, green pepper, apple, peach, tomato, onion, plum, kiwi, pears } \\
\text { Scots pine } \\
\text { Tomato, avocado, oranges, potatoes, pepper, cucumber } \\
\text { Lemon, orange } \\
\text { Apple, watermelon } \\
\text { Tomato } \\
\text { Grapefruit, tangerines } \\
\text { Avocado, pumpkin, tomato } \\
\text { Lemon } \\
\text { Chicken beaks } \\
\text { Grapefruit } \\
\text { Tomato } \\
\text { Eggs } \\
\text { Chicken beaks } \\
\text { Chicken beaks } \\
\text { Eggs } \\
\text { Citrus fruits } \\
\text { Citrus leaves } \\
\text { Cavendish banana } \\
\text { Coconut } \\
\text { Citrus leaves } \\
\text { Apple and banana } \\
\text { Cavendish banana } \\
\text { Citrus fruits }\end{array}$ & $\begin{array}{c}\text { Drouillard and Kanner (1997) } \\
\text { Drouillard and Kanner (1999) } \\
\text { Barcikowski et al. (2006) } \\
\text { Etxeberria et al. (2006) } \\
\text { Heck et al. (2007) } \\
\text { Longobardi (2007) } \\
\text { Yuk et al. (2007) } \\
\text { Sood et al. (2008) } \\
\text { White (2008) } \\
\text { Etxeberria et al. (2009) } \\
\text { Fröschle (2009) } \\
\text { Sood et al. (2009a) } \\
\text { Sood et al. (2009b) } \\
\text { Danyluk et al. (2010) } \\
\text { Griffiths and Fox. (2011) } \\
\text { Mc Inerney et al. (2011a) } \\
\text { Mc Inerney et al. (2011b) } \\
\text { Parker (2011) } \\
\text { Danyluk et al. (2013) } \\
\text { Marx et al. (2013) } \\
\text { Etxeberria and Gonzalez (2014) } \\
\text { Nasution and Rath (2015) } \\
\text { Zighelboim (2015) } \\
\text { Etxeberria et al. (2016) } \\
\text { Hoult, (2017) } \\
\text { Nasution and Rath (2017) } \\
\text { Chih-Hsing et al. (2019) }\end{array}$ \\
\hline
\end{tabular}

several years marketing strategies have focused on laser marking on apples using UV laser systems (Becker, 2015). DPM together with two dimensional (2D) barcodes such as Quick Response (QR) and Data Matrix (DM) codes are usually used for marking produce (Li et al., 2016). DM codes are used extensively in DPM because of their property of storing data in two directions unlike one dimensional (1D) barcodes. Also, DM codes are robust and not susceptible to printing defects on the produce like 1D barcodes (GS1, 2018; MVTec, 2018).

Different from products of other industries that tend to be uniform in color, size, and shape, produce of the agricultural and horticultural industry are not. Agricultural produce of the same variety or species come with different sizes, shapes and colors (Kondo, 2010). These problems, along with other factors such as the type of skin, and water content in the produce, make it difficult to directly mark barcodes on agricultural produce. The main factors influencing decoding of 2D barcodes on directly marked produce are laser energy $(\mathrm{W} / \mathrm{s})$, surface contrast, print growth, barcode size, laser power (W) and edge length of the barcode. Print growth is simply the growth or shrinkage of the barcode size when marking from its intended target size (fig. 1). Although print growth is not normally considered during laser marking on agricultural produce, it is important when considering using low and high laser energy. As the size of DM code shrinks or grows, its readability and quality are affected by print growth (Li et al., 2016). Print growth is divided into three groups: shrinkage ( $<100 \%$ where the pattern marked is incomplete), perfect (equal to $100 \%$ ) and growth $(>100 \%$ where there is increase in the barcode size and burning of the edges of the barcode) (Jangsombatsiri \& Porter, 2006, 2007; GS1, 2015; Li et al., 2016). The Heat Affected Zone (HAZ) affects the print growth of small size modules and bigger ones (Li et al.,
2016). Also, a small HAZ will lead to shrinkage at the edges of big DM codes as enough heat is not applied to complete the marking. According to literature some work has been done on the effect of laser energy and power on readability of DM codes (table 1) but at high marking energies. Laser markings of apples with laser powers of 5-10 W (0.19$0.38 \mathrm{~J} \mathrm{~mm}^{-2}$ ) by Marx et al. (2013) resulted in decreased detection and reduction in the quality of the laser makings due to increase carbonization, browning and ablation in the HAZ. Therefore, they proposed that for future work markings should be carried out with energies less than $0.19 \mathrm{~J} \mathrm{~mm}^{-2}$ as low laser energies reduce the risk of tissue shrinkage, water loss, and risk of infection.

Barcode size is another important factor in successful decoding of marked DM code on horticultural and biological products. Fröschle et al. (2009) applied $10 \times 10 \mathrm{~mm}$ and $12 \times 12 \mathrm{~mm}$ DM codes to chicken beaks and proposed that $10 \times 10 \mathrm{~mm}$ DM codes produced the better result. Also, Marx et al. (2013) showed that the edge length and spaces between the barcodes are critical for readability of $2 \mathrm{D}$ barcodes. The wider the spaces between the barcode patterns, the better the detection. However, in their study using a small code length, $3 \times 3 \mathrm{~mm}^{2}$, no information was provided concerning the stability of the code for reading the markings during storage.

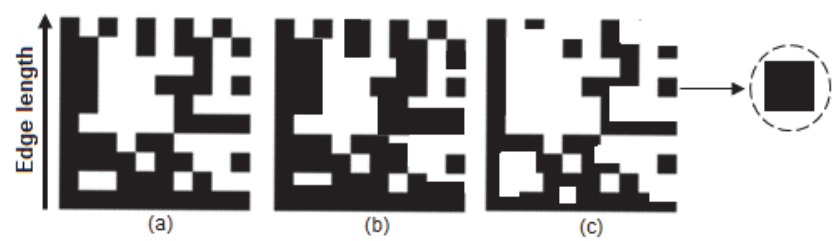

Figure 1. ECC200 Data Matrix encoded with 123456 showing: (a) perfect marking, (b) growth of the barcode, (c) shrinkage of the barcode and the individual module. 
Also, Nasution and Rath (2015) showed the effect of various DM code sizes and different modules $[6 \mathrm{~mm}(10 \times 10 \mathrm{mod}-$ ules), $8 \mathrm{~mm}(12 \times 12$ modules $), 10 \mathrm{~mm}$ ( $14 \times 14$ modules $)$, and $12 \mathrm{~mm}(16 \times 16$ modules $)]$ on readability on Cavendish banana. They showed that as the modules in the code increases the readability decreases. Furthermore, as the barcode size becomes smaller, the readability of the code decreases.

A good contrast between the marking and background of the product is required for successful decoding of the barcode (Ventura et al., 2016; Li et al., 2016; He and Joseph, 2017). Although laser marking and detection of 2D barcodes have been successful on some biological/horticultural products, there has been little information on the algorithms used for the detection of these products. Only Marx et al. (2013) and Nasution and Rath (2017) reported the image processing steps for detecting the DM codes by using the Halcon software (Halcon 11.0.1, MVTec Software GmbH, Munich, Germany).

Therefore, the objectives of this study were to determine the effect of low laser marking energies on print growth and the effect of barcode size and surface contrast on the quality and readability of 2D DM codes on an important horticultural produce like apple. The same module size $(10 \times 10 \mathrm{mod}-$ ules) but with different DM code sizes ( 8 and $10 \mathrm{~mm}$ ) was used to determine the stability of the barcode size on detection during storage.

\section{MATERIALS AND METHODS}

\section{EFFECTS OF LASER ENERGY AND PRINT GROWTH ON MARKINGS AND DETECTION ON GOLDEN DELICIOUS AND KANZI}

In the first experiment to determine the effect of laser energy and print growth on laser marking and detection, two varieties of apples (Malus domestica) 'Golden Delicious' and 'Kanzi' purchased from a local grocery supermarket were used. Fourteen apples were stored at a temperature of $16^{\circ} \mathrm{C}-17^{\circ} \mathrm{C}$ and relative humidity of $62 \%$ to determine the rate of deterioration during storage of 10 days. Seven laser powers were used for marking a DM code size of $\left[8 \times 8 \mathrm{~mm}^{2}\right.$, $\left(64 \mathrm{~mm}^{2}\right)$ ] (table 2). Therefore, seven laser energies were used for marking the apples (table 2). On an average it took $0.110 \mathrm{~s}$ per module to mark the barcode size of $8 \times 8 \mathrm{~mm}^{2}$. Twenty replications were done for each laser marking energy. Two fruits were chosen for each energy level and 10 replicates per fruit were marked.

Table 2. Laser energy ( $\mathrm{J}$ per module) applied on Golden Delicious and Kanzi based on laser power $(W)$ and marking time (s per module).

\begin{tabular}{cc}
\hline & $\begin{array}{c}\text { Energy }(\mathrm{J}) \\
\text { Code Size } 8 \times 8 \mathrm{~mm}^{2}\end{array}$ \\
\cline { 2 - 2 } Laser Power $(\mathrm{W})$ & $\mathrm{t}_{1}=0.110 \mathrm{~s}$ \\
\hline $\mathrm{p}_{1}=0.50$ & $\mathrm{p}_{1} \mathrm{t}_{1}=0.055$ \\
$\mathrm{p}_{2}=0.57$ & $\mathrm{p}_{2} \mathrm{t}_{1}=0.063$ \\
$\mathrm{p}_{3}=0.64$ & $\mathrm{p}_{3} \mathrm{t}_{1}=0.070$ \\
$\mathrm{p}_{4}=0.70$ & $\mathrm{p}_{4} \mathrm{t}_{1}=0.077$ \\
$\mathrm{p}_{5}=0.77$ & $\mathrm{p}_{5} \mathrm{t}_{1}=0.085$ \\
$\mathrm{p}_{6}=0.84$ & $\mathrm{p}_{6} \mathrm{t}_{1}=0.092$ \\
$\mathrm{p}_{7}=0.91$ & $\mathrm{p}_{7} \mathrm{t}_{1}=0.100$ \\
\hline
\end{tabular}

EFFECT OF BARCODE SIZE AND CONTRAST ON LASER MARKING AND DETECTION ON GOLDEN DELICIOUS AND RED JONAPRINCE

Two varieties of apples 'Golden Delicious' and 'Red Jonaprince' from the storage room of the Department of Fruit Science, University of Applied Sciences, Osnabrueck, Germany, were used for the second experiment studying the effects of barcode size and contrast on laser marking and detection. Twenty apples were stored at a temperature of $20^{\circ} \mathrm{C}$ and relative humidity of $78 \%$ for 10 days. These apples were chosen due to the difference in their peel colors. On an average it took $0.154 \mathrm{~s}$ per module to mark a barcode size of [10 $\left.\times 10 \mathrm{~mm}^{2},\left(100 \mathrm{~mm}^{2}\right)\right]$. Two fruits were chosen for each energy level and 10 replicates per fruit were marked. Therefore, 20 replications were performed for each laser marking energy. Table 3 below shows the laser energy (J per module) used for the experiment for both barcode sizes.

\section{LASER SETUP}

The laser tests were carried out in the Laboratory of the Department of Biosystems Engineering, University of Applied Sciences, Osnabrueck, Germany. The experimental setup similar to Marx et al. (2013) was used for all the experiments (fig. 2). The DM code was etched with a marking head $246 \mathrm{~mm}$ away from the apple (fig. 2). The laser (Synrad 48-5 carbon dioxide, Synrad Inc., Mukiltoe, Wash.) with wavelength of $10600 \mathrm{~nm}$, output power of $50 \mathrm{~W}$, speed of $380 \mathrm{~mm} / \mathrm{s}$ and SH3-200C marking head controlled by a personal computer and the laser marking software (WinMarkPro ${ }^{\circledR}$, Synrad Inc., Mukiltoe, Wash.) with the following laser parameters (table 4) was used for etching the ECC200 DM codes onto the products. Based on the GS1 DM symbol attributes (square form), 10×10 modules was used for marking the apples. The number 123456 was encoded on the DM for marking based on the maximum data capacity of the modules that were selected. The DM code was designed and saved in a bit map format at $45^{\circ}$ angle to ensure better marking on the product.

\section{Image ACQuisition and Processing of the Data MATRIX CODE}

The proposed algorithm (fig. 3) for decoding the laser markings was divided into two phases (preprocessing and detection phases). For the ECC200 DM codes the main aim was to find the ' $\mathrm{L}$ '-shape pattern which runs down from the left side and across the bottom peripheral cells of the code on the fruit (fig. 1a). At the beginning, images of the DM marked on the apples were acquired using a camera (Canon EOS Digital Rebel XSI/450D with a zoom lens of EF-S 18$55 \mathrm{~mm}, \mathrm{f3.5}-5.6 \mathrm{IS}$, Tokyo, Japan) held on a tripod stand

Table 3. Laser energy (Joule per module) applied on Golden Delicious and Red Jonaprince based on the laser power (W) and marking time (s per module).

\begin{tabular}{ccc}
\hline & $\begin{array}{c}\text { Energy }(\mathrm{J}) \\
\text { Code Size } 8 \times 8 \mathrm{~mm}^{2}\end{array}$ & Code Size $10 \times 10 \mathrm{~mm}^{2}$ \\
\cline { 2 - 3 } Laser Power $(\mathrm{W})$ & $\mathrm{t}_{1}=0.110 \mathrm{~s}$ & $\mathrm{t}_{2}=0.154 \mathrm{~s}$ \\
\hline $\mathrm{p}_{1}=0.50$ & $\mathrm{p}_{1} \mathrm{t}_{1}=0.055$ & $\mathrm{p}_{1} \mathrm{t}_{2}=0.077$ \\
$\mathrm{p}_{2}=0.57$ & $\mathrm{p}_{2} \mathrm{t}_{1}=0.063$ & $\mathrm{p}_{2} \mathrm{t}_{2}=0.088$ \\
$\mathrm{p}_{3}=0.64$ & $\mathrm{p}_{3} \mathrm{t}_{1}=0.070$ & $\mathrm{p}_{3} \mathrm{t}_{2}=0.099$ \\
$\mathrm{p}_{4}=0.70$ & $\mathrm{p}_{4} \mathrm{t}_{1}=0.077$ & $\mathrm{p}_{4} \mathrm{t}_{2}=0.108$ \\
\hline
\end{tabular}




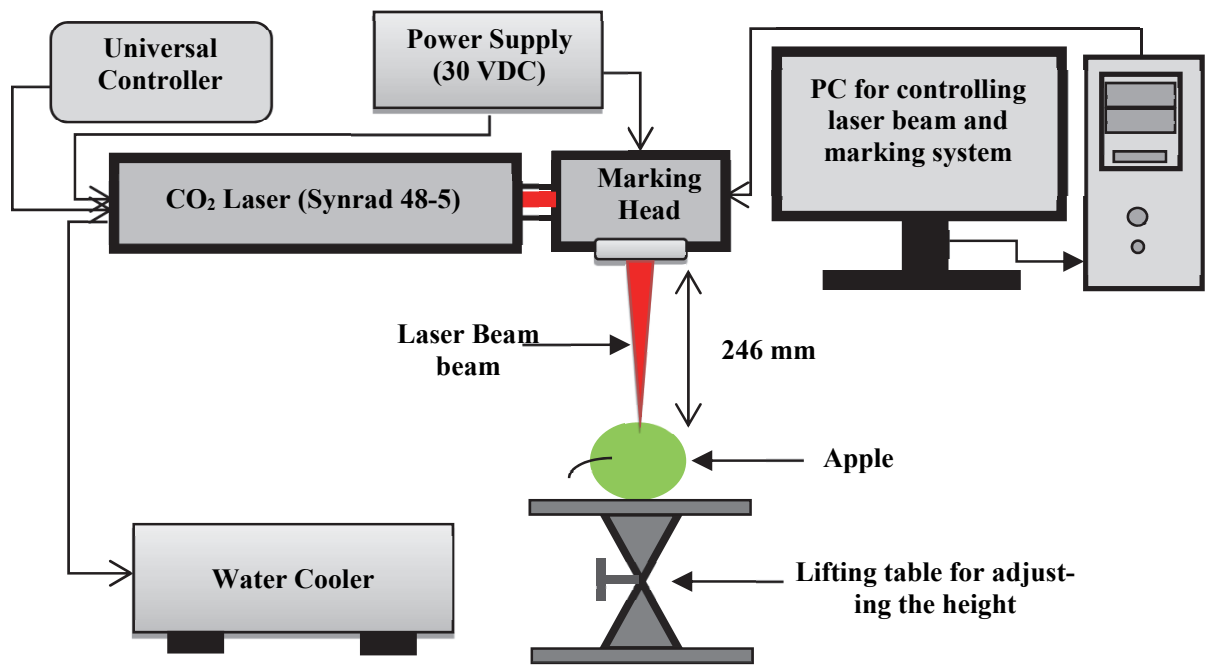

Figure 2. Laser marking experiment setup showing the $\mathrm{CO}_{2}$ laser, marking head, product positioning, and computer-based control.

$30 \mathrm{~cm}$ away from the apple. The images were acquired under lighting conditions using 3 Osram L 18 W/ 840 Lumilux $(59 \mathrm{~cm})-$ Cool White fluorescent tubes (Osram $\mathrm{GmbH}, \mathrm{Mu}-$ nich, Germany). A lighting box system of $(70 \times 56 \times 56 \mathrm{~cm})$ was designed and placed in a dark photo laboratory so that only light from the fluorescent tubes was used. The light system was covered by an aluminum foil emergency blanket to keep the light within the system. The image processing software (Halcon 11.0.1, MVTec Software GmbH, Munich, Germany) was used in analyzing the images.

\section{Preprocessing}

Due to the effects of the peel colors of the apples on the images, two different preprocessing approaches were used for decoding the images. For Golden Delicious, with a good contrast between the markings and peel, the following image preprocessing was done. The images were acquired by placing the apples $25 \mathrm{~cm}$ below the lights in the box and $30 \mathrm{~cm}$ away from the camera. Having acquired the images, the marked DM codes (fig. 4a) were filtered to reduce noise in the background of the image. A gray value opening of the image with a $7 \times 7$ rectangular mask was performed on the images. Smoothing of the image to reduce noise and suppress unwanted objects was then done using the $3 \times 3$ Median filter (fig. 4b). The image was then transformed from the three channel RGB (red, green, blue) color space to the HSV (hue, saturation, value) color space (see Halcon 11.0.1, MVTec Software GmbH, Munich, Germany). The most useful channels $\mathrm{S}$ and $\mathrm{V}$ were then selected and combined by

Table 4. Laser marking parameters for marking the ECC200 Data Matrix code on the apples.

\begin{tabular}{lc}
\hline \multicolumn{1}{c}{ Marking Parameters } & Value \\
\hline Velocity $(\mathrm{mm} / \mathrm{s})$ & 381 \\
Resolution (dots per in.) & 1000 \\
Pline start delay $(\mu \mathrm{s})$ & 100 \\
Pline end delay $(\mu \mathrm{s})$ & 450 \\
Interseg delay $(\mu \mathrm{s})$ & 350 \\
Off vector delay $(\mu \mathrm{s})$ & 300 \\
Bi-directional raster $(\mathrm{Yes} / \mathrm{No})$ & Yes \\
Interseg break angle $\left({ }^{\circ}\right)$ & 30 \\
Off vector velocity $(\mathrm{mm} / \mathrm{s})$ & 1905 \\
Off vector resolution $($ dots per in.) & 300 \\
Raster scan direction (horizontal/vertical) & Horizontal \\
\hline
\end{tabular}

pixel averaging (i.e., by computing the arithmetic mean or average of the intensity values for each pixel in the captured image) (fig. 4c and 4d).

For Red Jonaprince and Kanzi, with poor contrast between the peel color and the laser marking, a different approach was adopted to preprocess the images. Having acquired the images example of Red Jonaprince (fig. 5a), the edges of the image (fig. 5b and 5c) were then detected using the $3 \times 3$ Sobel operator (eq. 1) (Jähne et al., 1999; Marx et al., 2013). Hough transformation was then performed to

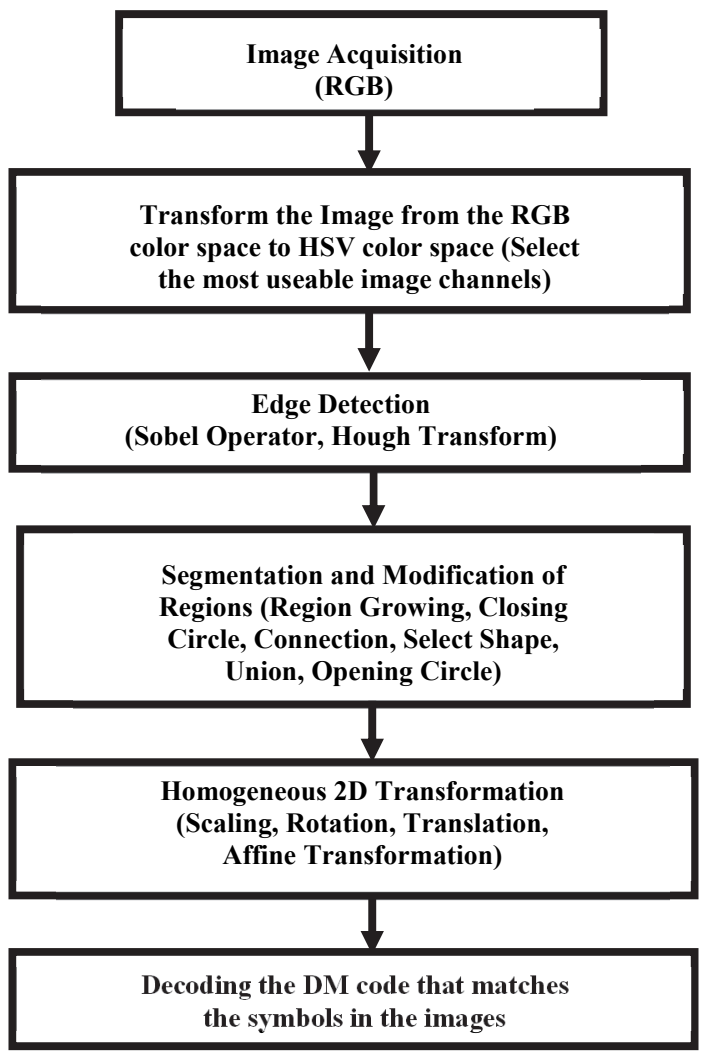

Figure 3. Flow chart showing the proposed image processing algorithm and the shaped based matching algorithm for decoding the laser images on the apples. (see also Halcon 11.0.1 Documentation, MVTec Software GmbH, Munich, Germany). 


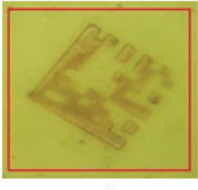

a)

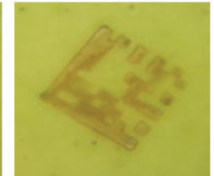

b)

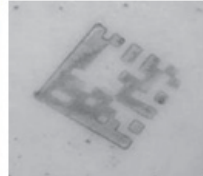

c)

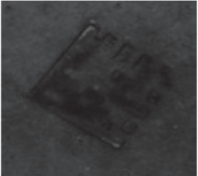

d)
Figure 4. (a) Marked area of interest of DM code, (b) smoothing using $3 \times 3$ Median filter, (c) $\mathrm{S}$ channel, and (d) $\mathrm{V}$ channel.

connect the lines at the edge of the image by using local gradient direction and converting them in the normal form. Hough transform allowed the mapping of all the possible straight lines through a minimum number of 10 points at an angle resolution of $1^{\circ}$ and allowed direction of uncertainty of $2^{\circ}$. A Gaussian filter of size $5 \times 5$ was used to smooth the image to detect all possible edge points of the markings that lie along the straight line of the image (Duda and Hart, 1972; Marx et al., 2013). Smoothing of the image to reduce noise and suppress unwanted objects was then done using the $3 \times 3$ Median filter (fig. 5d). The image was then transformed from the three channel RGB color space to the HSV color space. The most useful channels $\mathrm{S}$ and $\mathrm{V}$ were then selected and combined by pixel averaging (fig. $5 \mathrm{e}$ and $5 \mathrm{f}$ ).

$$
G x=\left[\begin{array}{ccc}
1 & 2 & 1 \\
0 & 0 & 0 \\
-1 & -2 & -1
\end{array}\right] \text { and } G y=\left[\begin{array}{ccc}
1 & 0 & -1 \\
2 & 0 & -2 \\
1 & 0 & -1
\end{array}\right]
$$

where $\mathrm{G} x$ is the mask in the $\mathrm{x}$ direction and $\mathrm{G} y$ is the mask in the $y$ direction.

\section{Decoding of the Image}

The following steps to decode the images after preprocessing were used for Golden Delicious, Kanzi and Red Jonaprince. The images were further processed using mathematical morphological operators (region growing, closing, connection, select shape, union, and opening). Affine transformation was then performed to preserve the points and straight lines of the image. Dilation was performed to enlarge the transformed region of the image, and the gaps smaller than the rectangular mask in the interior of the regions were closed. The shape and size of the region of interest was maintained by performing a rigid affine a)

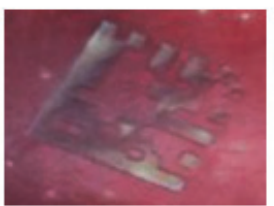

d)

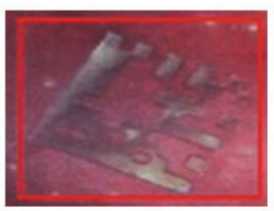

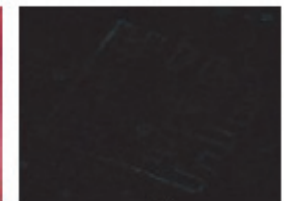

b)

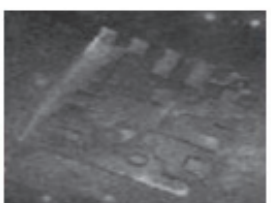

e)

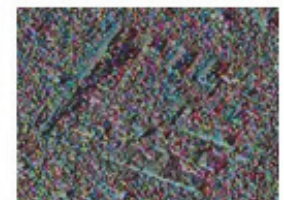

c)

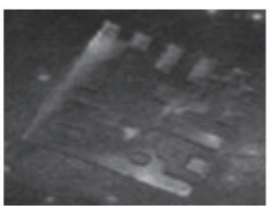

f)
Figure 5. (a) Marked area of interest of DM code, (b) edge amplitude, (c) edge direction, (d) smoothing using $3 \times 3$ Median filter, (e) $\mathrm{S}$ channel, and (f) $\mathrm{V}$ channel. transformation using a rotation and a translation vector, from a point and two corresponding angles. Finally, the images were detected using the shape-based matching algorithm by performing scaling, rotation, translation and affine transformation on the image (fig. 3). A score of one was given when the algorithm detected the DM code and zero if it was not detected. The successful rate of detection was based on the formula below (eq. 2).

$$
S=\frac{D}{N} \times 100(\%)
$$

where

$\mathrm{S}=$ success,

$\mathrm{D}=$ detection,

$\mathrm{N}=$ replication $(20)$.

\section{RESULTS AND DISCUSSION}

\section{EFFECTS OF LASER ENERgY AND PRINT GROWTH ON MARKINGS AND DETECTION ON GOLDEN DELICIOUS AND KANZI}

Figure 6 shows the effect of increasing laser energy and days of storage on successful decoding of DM on Golden Delicious and Kanzi. There was a $100 \%$ decoding for Golden Delicious at $0.070 \mathrm{~J} \mathrm{~mm}^{-2}$ for all the 10 days of storage. Generally, there was rather low success with Kanzi. The laser energy either resulted in low print growth/shrinkage, i.e. incomplete marking of the DM, or no printing of the DM on the apples (fig. 7). There was no marking of the DM at the lowest marking energy. According to Ventura et al. (2016) and Li et al. (2016) this is because the HAZ temperature was insufficient for oxidation reactions to occur and for a high contrast module of the DM code to appear on the apples. At the last two energies, ablation, carbonization and browning occurred on the markings on the apples. According to Marx et al. (2013) and Li et al. (2016) the HAZ temperature was too high resulting in shrinkage and poor quality of the marking (fig. 7). Shrinkage occurred for all the products that were marked with the highest energy level (fig. 7). Due to various factors such as barcode size, laser energy, variety, and skin surface properties of the product, it is unavoidable that there will be some shrinkage or growth of the DM code during the marking process (GS1, 2015). Shrinkage leads to failure in readability of the barcodes as the "L" pattern of the DM code could not be detected.

In both apples, the energy and the skin affected the print growth, with the highest energy resulting in increased shrinkage. Li et al. (2016) reported that the shrinkage of the markings can be attributed to insufficient power at the end of the marking. Furthermore, the effect of print growth on DM code can be attributed to the inertia of the laser beam. In our experiments the initial energy of marking by the laser beam was higher than at the final stages of marking, resulting in shrinkage of the DM code (consistent with the report of Li et al., 2016). They reported that when Nd:YAG Qswitched lasers are used in marking of DM code the first pulses are always more powerful than the later ones resulting in a deeper and wider marking in the initial stages. The speed of the initial and final stages of travel of the laser beam is slower than what was set for marking. Therefore, the laser 


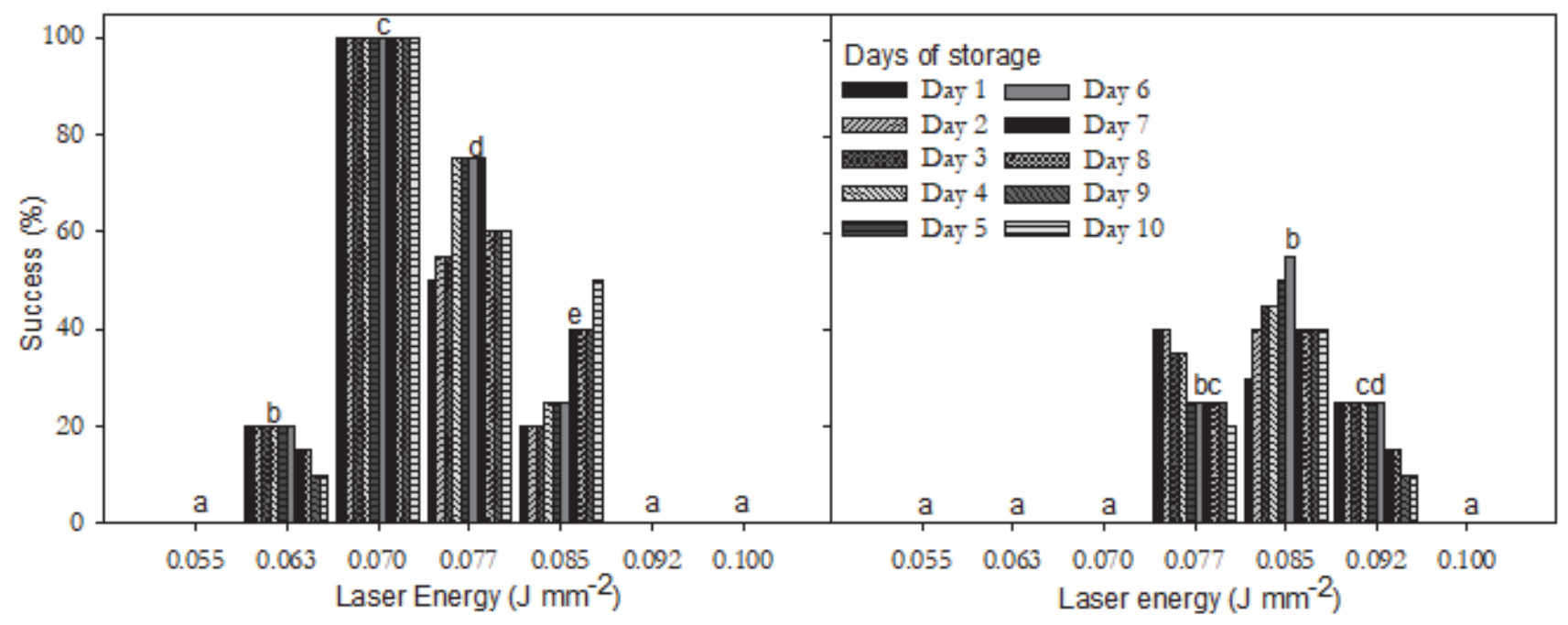

(a) Golden Delicious

(b) Kanzi

Figure 6. Effect of energy and days of storage on successful decoding of Data Matrix on (a) Golden Delicious and (b) Kanzi (using Tukey Multiple Comparison test, $\alpha=0.05, \mathrm{n}=\mathbf{2 0}$ for both apples).

beam works at a speed lower than what was set when the distance the beam travels is short, causing shrinkage of the DM codes on the products (Synrad 2012; Li et al., 2016). Also, Jangsombatsiri and Porter (2007) showed that the direction of the print growth (X- or Y-axis) has a significant effect on the quality of the DM code. They reported that the print growth in the $\mathrm{X}$-axis had more effect on the quality and final grade of the DM code than the print growth in the Yaxis. In contrast, our experiments showed that the marking of the DM code in the Y-axis had a more critical effect on the final marking and quality of the DM code than the marking of the DM in the $\mathrm{X}$-axis.

Furthermore, during storage of the apples, ripening occurs, resulting in increased ethylene production and rise in cellular respiration as the days of storage increased. Increased oxidation occurs around the areas of the apples marked with the DM code resulting in a browning and better contrast for the marking as the days of storage increases. According to Nasution and Rath (2017), laser power and time are responsible for producing high contrasts in the DM codes on Cavendish banana. They showed that the contrast values increase as the days of storage increased. In our experiment, as the days of storage increased, successful rate of decoding of the barcodes for Golden Delicious increased whereas that of Kanzi decreased. This can be attributed to a better contrast between the marking and the yellowish green skin of Golden Delicious and a poor contrast between the markings and the deep reddish yellow skin of Kanzi (fig. 6).

\section{EFFECT OF BARCODE SIZE AND CONTRAST ON DM READABILITY ON GOLDEN DELICIOUS AND RED JONAPRINCE}

A significant contrast between the color of the apple and the laser markings is necessary for successful decoding of the barcode, which agrees with what other researchers reported (Wang and Madej, 2014; Li et al., 2016; Ventura et al., 2016; He and Joseph, 2017; Bassoli, 2018). In our experiment, the comparison of the effect of energy and barcode size on detection after 10 days of storage showed that there

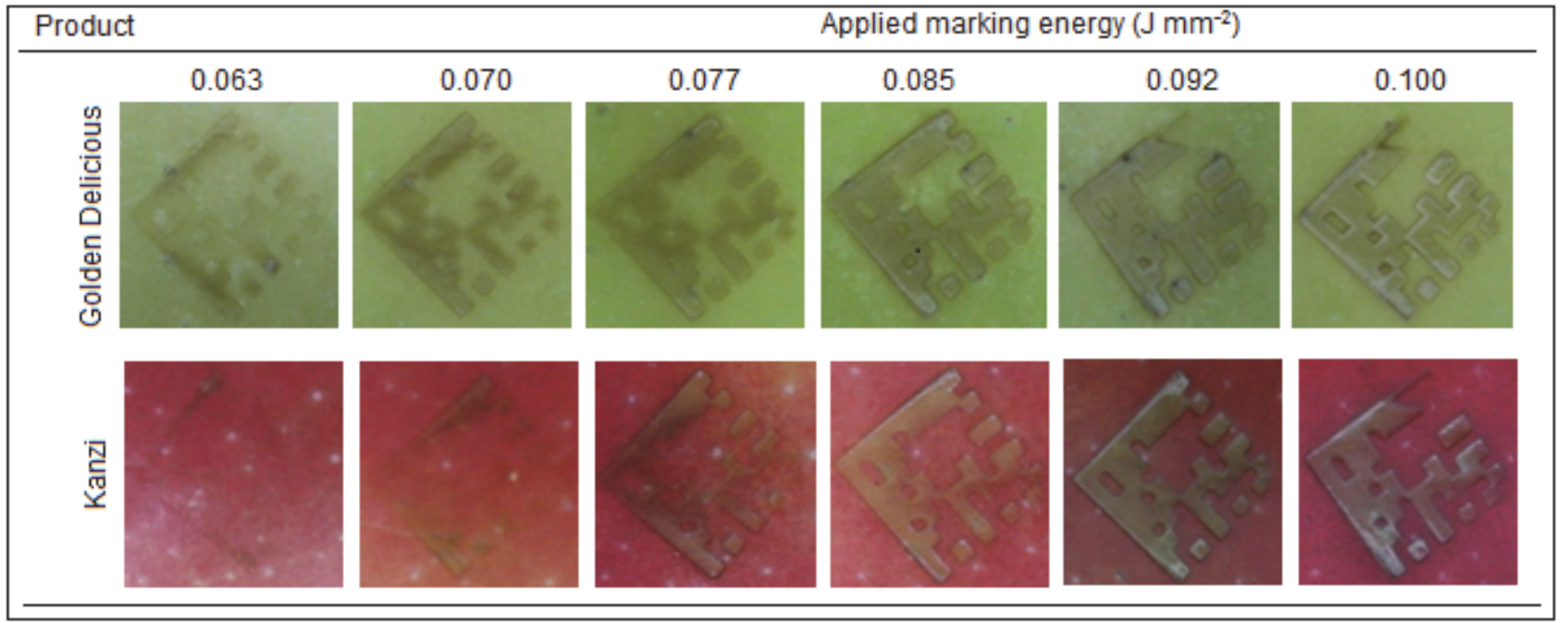

Figure 7. Effect of increasing marking energy on printing of Data Matrix on the skin of Golden Delicious and Kanzi. 
was good detection for both barcode sizes of Golden Delicious. There was rather poor detection for Red Jonaprince, with detection only at the highest marking energy for both barcode sizes (fig. 8c and 8d). This can be attributed to the contrast between the markings and peel color of both apples. In addition, Bassoli (2018) and GS1 (2018) reported that in order to reduce interference of noise and distinguish between the dark and light elements of the markings, strong contrast is needed to create a strong signal. This results in an increased chance of decoding the barcode at even longer distances. Therefore, the better detection of the markings on Golden Delicious in our experiment can be attributed to the better contrast between the DM code and the yellowish green color of the Golden Delicious as the days of storage increased. Moreover, the poor detection of the Red Jonaprince is due to the weak contrast between the DM and the dark reddish color of the Red Jonaprince as the days of storage increased (fig. 8).

Furthermore, the choice of marking energy required to successfully decode the DM depends on the product. According to Marx et al. (2013), an increase in marking energy leads to carbonization, ablation and browning in the HAZ as a result of increased water loss from the apples, which

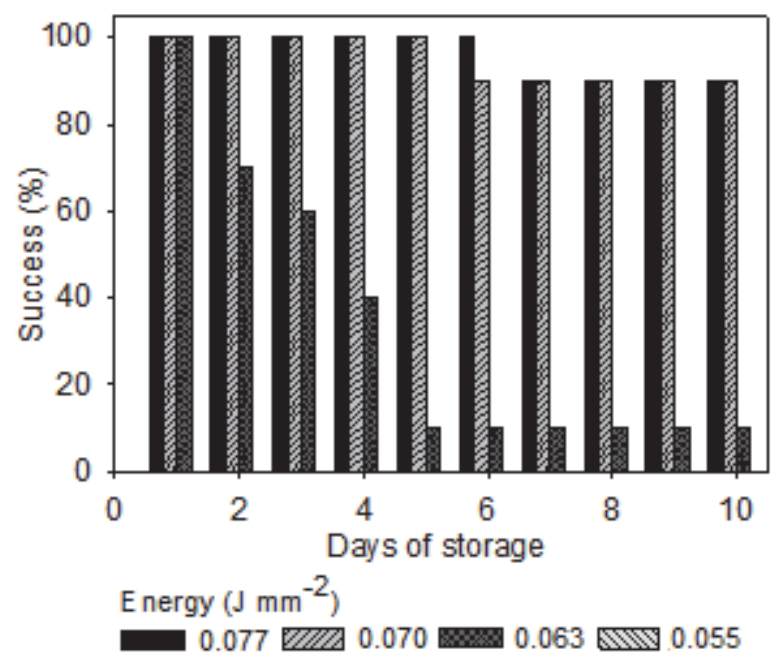

a) Code size $8 \times 8 \mathrm{~mm}^{2}$, Golden Delicious

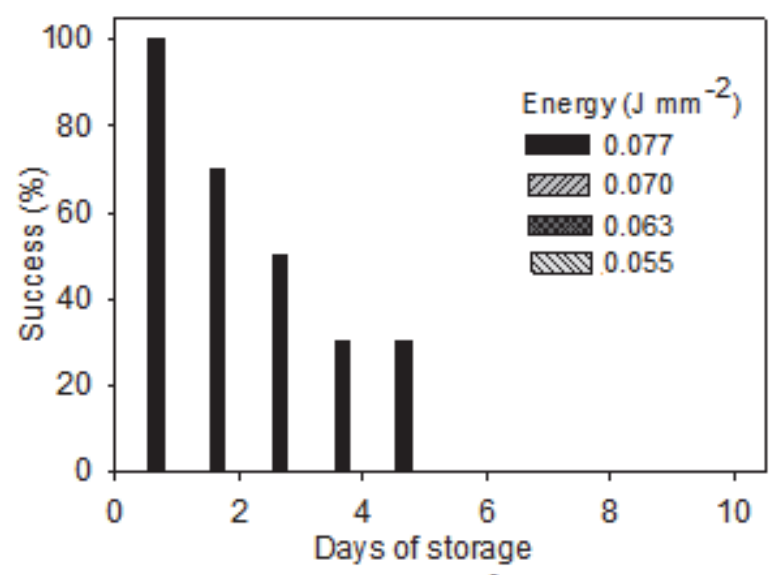

c) Code size $8 \times 8 \mathrm{~mm}^{2}$, Red Jonaprince negatively affects the decoding of the barcode. Therefore, the low energy levels used in our experiments resulted in the markings being visible on the next day. However, there was no marking at the lowest energies for both barcode sizes. $\mathrm{Li}$ et al. (2016) stated that this is due to insufficient energy for oxidation reaction to occur on the surface of the apples. Moreover, as the laser marking energy increased, oxidation reactions on the skin of the apples was caused by the heat from the laser, leading to carbonization, ablation and browning. According to Marx et al. (2013), increase in the laser marking energy affected the decoding of the correctly shaped patterns one day after marking. In our experiments there was a better detection at the highest marking energy and bigger barcode size for 10 days (fig. $8 b$ ).

Furthermore, the barcode size played a significant role in successful detection of the barcode (Marx et al., 2013; Nasution and Rath, 2015; Li et al., 2016). Marx et al. (2013) suggested that the minimum pattern size (edge length) for marking apples was $3 \mathrm{~mm}$. Also, they reported that an increase in the pattern size of apples from 3 to $8 \mathrm{~mm}$ led to better marking and decoding as the minimum distance between the modules increased. Based on the detection at the various sizes of our experiment, marking at a barcode size of

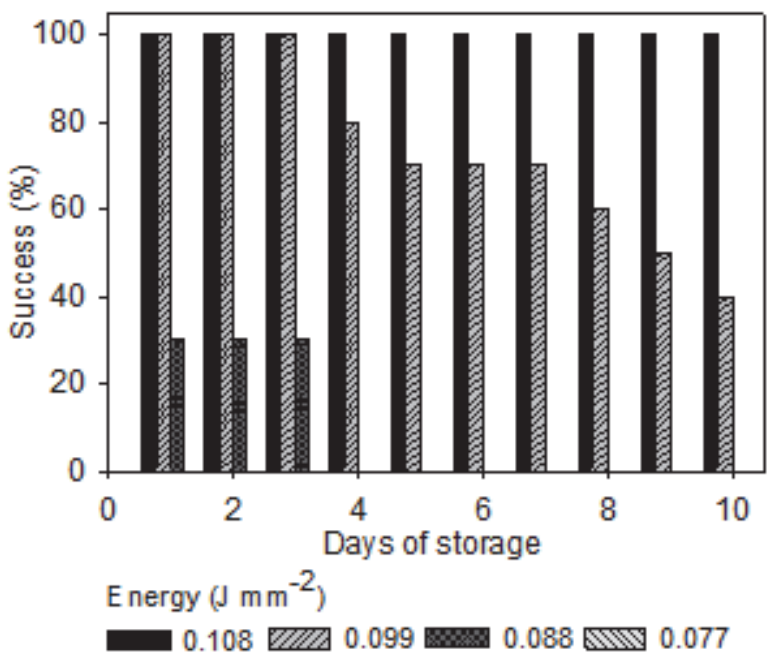

b) Code size $10 \times 10 \mathrm{~mm}^{2}$, Golden Delicious

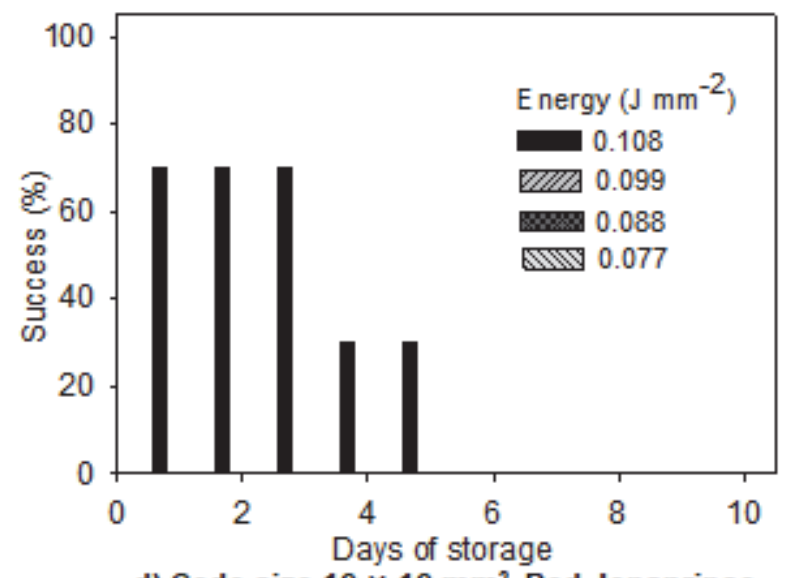

d) Code size $10 \times 10 \mathrm{~mm}^{2}$, Red Jonaprince

Figure 8. The effects of energy and barcode size on Data Matrix code detection on (a and b) Golden Delicious and (c and d) Red Jonaprince $(\mathrm{n}=\mathbf{2 0}$ for both apples). 
$10 \times 10 \mathrm{~mm}^{2}$ used more energy compared to $8 \times 8 \mathrm{~mm}^{2}$. This resulted in a better detection of the DM at $10 \times 10 \mathrm{~mm}^{2}$ for Golden Delicious at the highest marking energy for 10 days (fig. 8b). However, this resulted in increased ablation, carbonization, and browning in the HAZ. Furthermore, with the subsequent lower energies, there was better detection with barcode size $8 \times 8 \mathrm{~mm}^{2}$ compared to $10 \times 10 \mathrm{~mm}^{2}$ (fig. $8 \mathrm{a}$ ). Since the aim is to minimize the effect of heat damage on the skin of the apples, barcode size $8 \times 8 \mathrm{~mm}^{2}$ is recommended for marking as it also resulted in $100 \%$ detection for 6 days at $0.077 \mathrm{~J} \mathrm{~mm}^{-2}$ for Golden Delicious (fig. 8a).

\section{Conclusions}

The findings of this research are that laser energy, barcode size, print growth, type of product, contrast between the markings, and the color of the products, inertia of the laser system and days of storage all singularly or in combination with each other influence the readability of laser DM codes and implementation on apples.

1. The proposed algorithm is currently only working successfully on Golden Delicious with $100 \%$ detection for 10 days at energy of $0.108 \mathrm{~J} \mathrm{~mm}^{-2}$ using a barcode size of $10 \times 10 \mathrm{~mm}^{2}$.The contrast between the markings and skin resulted in better detection for Golden Delicious than Red Jonaprince and Kanzi.

2. High laser marking energy resulted in ablation, browning and carbonization, which decreased detection of the DM.

3. The bigger barcode size $10 \times 10 \mathrm{~mm}^{2}$ had better detection as a result of higher energy being used in marking. However, since this resulted in ablation, carbonization, and browning of the HAZ on the skin, the smaller barcode size $8 \times 8 \mathrm{~mm}^{2}$ is recommended as it gave a better marking at the lower marking energies.

4. The working direction of the laser beam affected the print growth of the DM code as the energy of the laser beam at the initial marking stage was higher than at the final stage.

5. Finally, oxidation around the marked DM code resulted in better contrast of the markings as the days of storage increased resulting in better detection of the DM code for Golden Delicious.

It has to be stated that the experiments were done with a $\mathrm{CO}_{2}$ laser because of the high absorption of laser energy by apples within the infrared waveband. Therefore, one should be careful in transferring the results to other laser wavelengths and configurations, especially classical marking lasers in the UV or blue waveband. Nevertheless, successful detection of DM on horticultural products is still a challenge. For example, in our experiments only Golden Delicious had successful detection. More marking systems with different wavelengths, laser beam parameters and energy settings, and more varieties of apples and other horticultural products must be analyzed with the proposed algorithm to determine usability in the near future.

\section{ACKNOWLEDGEMENTS}

The authors gratefully acknowledge the cooperation of the University of Applied Sciences Osnabrück, Biosystems Engineering Laboratory for the assistance and use of the laboratory for the experiments. Thanks a lot to Mrs. Deborah Lynn Kious-Hnat for her time for proofreading the article.

\section{REFERENCES}

Barcikowski, S., Koch, G., \& Odermatt, J. (2006). Characterisation and modification of the heat affected zone during laser material processing of wood and wood composites. Holz als Roh- und Werkstoff, 64(2), 94-103. https://doi.org/10.1007/s00107-0050028-1

Bassoli, E. (2018). Direct part marking of Inconel 718. Int. J. Appl. Eng. Res., 13(5), 2235-2241.

Becker, W. (2015). Hein Lühs ist Entdecker des Bikini-Effektes und Erfinder des Laser-Apfels. Business \& People. Retrieved from https://www.business-people-magazin.de/2015/07-2015/beiihm-wachsen-aepfel-mit-herz-2060/

Chih-Hsing, L., Ta-Lun, C., Tzu-Yang, P., Chen-Hua, C., WeiGeng, P., \& Chi-Chun, W. (2019). An intelligent robotic system for handling and laser marking fruits. In H. H. Allen, M. Mitsutaka, C. K. Tsai, \& S. Shana (Eds.), Technologies and ecoinnovation towards sustainability I. Eco design of products and services (pp. 75-88). Singapore: Springer. https://doi.org/10.1007/978-981-13-1181-9 7

Danyluk, M., Friedrich, L., Sood, P., \& Etxeberria, E. (2013). Growth or penetration of Salmonella into citrus fruit is not facilitated by natural-light labels. Food Control, 34, 398-403. https://doi.org/10.1016/j.foodcont.2013.04.036

Danyluk, M., Interiano, L., Friedrich, L., Schneider, K., \& Etxeberria, E. (2010). Natural-light labeling of tomatoes does not facilitate growth or penetration of Salmonella into the fruit. J. Food Prot., 73, 2276-2280. https://doi.org/10.4315/0362028X-73.12.2276

Denkena, B., Grove, T., \& Seibel, A. (2016). Direct part marking by vibration assisted face milling. Procedia Technology, 26, 185191.

Drouillard, G., \& Kanner, R. W. (1997). Method of laser marking of produce. U.S. Patent No. 5660747.

Drouillard, G., \& Kanner, R. W. (1999). Produce marking system. U.S. Patent No. 5897797.

Duda, R. O., \& Hart, P. E. (1972). Use of the Hough transformation to detect lines and curves in pictures. Commun. ACM, 15, 11-15. https://doi.org/10.1145/361237.361242

Etxeberia, E., Miller, W. M., \& Achor, D. (2006). Anatomical and morphological characteristics of laser etching depressions for fruit labeling. HortTechnol., 16(3), 527-532. https://doi.org/10.21273/HORTTECH.16.3.0527

Etxeberria, E., \& Gonzalez, P. (2014). The use of laser light to enhance penetration of antimicrobials into citrus leaves. Proc. Florida State Hortic. Soc., 127, 75-77.

Etxeberria, E., Gonzalez, P., Borges, A., \& Brodersen, C. (2016). The use of laser light to enhance the uptake of foliar applied substances into citrus (Citrus sinensis) leaves. Appl. Plant Sci., 4(1), 1-10. https://doi.org/10.3732/apps.1500106

Etxeberria, E., Narciso, C., Sood, P., Gonzalez, P., \& Narciso, J. (2009). The anatomy of a laser label. Proc. Florida State Hortic. Soc., 122, 347-349.

Froschle, H. K., Gonzales-Barron, U., McDonnell, K., \& Ward, S. (2009). Investigation of the potential use of e-tracking and tracing of poultry using linear 2D barcodes. Comput. Electron. Agric., 66, 126-132. https://doi.org/10.1016/j.compag.2009.01.002

Griffiths, M. J., \& Fox, Y. E. (2011). Method and apparatus for laser marking objects. U.S. Patent. No. 8084712. 
GS1. (2015). GS1 2D barcode verification process implementation guidline. Retrieved from

https://www.gs1.org/docs/barcodes/2D_Barcode_Verification_P rocess_Implementation_Guideline.pdf

GS1. (2018). GS1 DataMatrix guideline. Retrieved from https://www.gs1.org/docs/barcodes/GS1_DataMatrix_Guideline. pdf

He, D., \& Joseph, E. B. (2017). System for and method of controlling illumination of direct part marking (DPM) targets to be read by image capture. U.S. Patent No. 9792477B1.

Heck, R. D., Gutierrez-Ibarra, J., \& Sheffler, J. B. (2007). Method and apparatus for non-invasive laser based labeling of plant products. U.S. Patent No. 2007/0252006.

Hoult, A. (2017). System and method of laser marking produce. U.S. Patent No. 20170239754A1.

Jahne, B., Scharr, H., Korkel, S., Haubecker, H., \& Geibler, P. (1999). Principles of filter design. Handbook of computer vision and applications (Vol. 2). Heidelberg: Academic Press.

Jangsombatsiri, W., \& Porter, D. J. (2007). Laser direct part marking of data matrix symbols on carbon steel substrates. $J$. Manuf. Sci. Eng., 129, 583-591. https://doi.org/10.1115/1.2716704

Jangsombatsiri, W., \& Poter, D. J. (2006). Artificial neural network approach to data matrix laser direct part marking. J. Intelligent Manuf., 17, 133-147. https://doi.org/10.1007/s10845-005-5517$\mathrm{X}$

Kang, Y.-S., \& Lee, Y.-H. (2013). Development of generic RFID traceability services. Comput. Ind., 64(5), 609-623. https://doi.org/10.1016/j.compind.2013.03.004

Kemeny, Z., Bozoki, S., Ilie-Zudor, E., \& Monostori, L. (2014). Low-cost extension of information transparency throughout the product life-cycle via optical identification and quality indication. Procedia CIRP, 25, 106-113. https://doi.org/10.1016/j.procir.2014.10.018

Kondo, N. (2010). Automation on fruit and vegetable grading system and food traceability. Trends Food Sci. Technol., 21(3), 145-152. https://doi.org/10.1016/j.tifs.2009.09.002

Li, X.-S., He, W.-P., Lei, L., Wang, J., Guo, G.-F., Zhang, T.-Y., \& Yue, T. (2016). Laser direct marking applied to rasterizing miniature Data Matrix Code on aluminum alloy. Opt. Laser Technol., 77, 31-39. https://doi.org/10.1016/j.optlastec.2015.08.020

Longobardi, R. (2007). Process and device for the marking of fruits through laser with, before the marking, a cleaning/drying step and, after the marking, a sealing of the marked area. European Patent No. EP1747838.

Marx, C., Hustedt, M., Hoja, H., Winkelmann, T., \& Rath, T. (2013). Investigations on laser marking of plants and fruits. Biosyst. Eng., 116(4), 436-446. https://doi.org/10.1016/j.biosystemseng.2013.10.005

Mc Inerney, B., Corkery, G., Ayalew, G., Ward, S., \& Mc Donnell, K. (2011a). Preliminary in vivo study on the potential application of a novel method of e-tracking to facilitate traceability in the poultry food chain. Comput. Electron. Agric., 77, 1-6. https://doi.org/10.1016/j.compag.2011.03.001
McInerney, B., Corkery, G., Ayalew, G., Ward, S., \& Mc Donnell, K. (2011b). A preliminary in vivo study on the potential application of a novel method of e-tracking in the poultry food chain and its potential impact on animal welfare. Comput.

Electron. Agric., 79, 51-62.

https://doi.org/10.1016/j.compag.2011.08.004

MVTec. (2018). Halcon 11.0.1 HDevelop user's guide. Munich, Germany. Retrieved from

https:/www.mvtec.com/fileadmin/Redaktion/mvtec.com/docum entation/manuals/hdevelop_users_guide.pdf

Nasution, I. S., \& Rath, T. (2015). Studies of laser marking on Cavendish banana. Proc. Annual Conf. DGG and BHGL - Short Communications. 5, pp. 1-5. German Society of Horticultural Sciences (DGG).

Nasution, I. S., \& Rath, T. (2017). Optimal laser marking of 2D data matrix code on Cavendish banana. Res. Agric. Eng., 63(4), 172179. https://doi.org/10.17221/26/2016-RAE

Parker, B. E. (2011). Method and apparatus for marking egg with an advertisement, a freshness date and a traceability Code. U.S. Patent No. 7951409.

Pullman, N. (2017). Swedish supermarkets replace sticky labels with laser marking. Retrieved from https://www.theguardian.com/sustainablebusiness/2017/jan/16/ms-and-swedish-supermarkets-ditchsticky-labels-for-natural-branding

Sood, P., Ference, C., Narciso, J., \& Etxeberria, E. (2008). Effects of laser labeling on the quality of tangerines during storage. Proc. Florida State Hortic. Soc., 121, 297-300.

Sood, P., Ference, C., Narciso, J., \& Etxeberria, E. (2009a). Laser marking: A novel technology to label Florida grapefruit.

HortTechnol., 19, 504-510. https://doi.org/10.21273/HORTSCI.19.3.504

Sood, P., Ference, C., Narciso, J., \& Etxeberria, E. (2009b). Laser labeling, a safe technology to label produce. Proc. ASHS Annual Conf. (p. 2391). American Society of Horticultural Science.

Synrad. (2012). WinMarkpro laser marking software user guide version 6.3. Retrieved from https://synrad.com/sites/default/files/201706/Operators\%20Manual\%20WinMarkPro.pdf

Tekin, E. (2014). A method for traceability and "as-built product structure" in aerospace industry. Procedia CIRP, 17, 351-355. https://doi.org/10.1016/j.procir.2014.01.053

Ventura, C., Aroca, R., Antonialli, A., Abrao, A., Campos, R. J., \& Camara, M. (2016). Towards part lifetime traceability using machined quick response codes. Procedia Technol., 26, 89-96. https://doi.org/10.1016/j.protcy.2016.08.013

Wang, M. X., \& Madej, D. J. (2014). Apparatus for and method of electro-optically reading direct part marking indicia by image capture. U.S. Patent No. US8690063B2.

White, L. (2008). Laser leaves mark on fruit. Weekly Times Now. Melbourne, Australia: Herald \& Weekly Times Pty. Ltd.

Yuk, H., Warren, B., \& Schneider, K. (2007). Infiltration and survival of Salmonella spp. on tomato surfaces labeled using a low-energy carbon dioxide laser device. HortTechnol., 17, 6771. https://doi.org/10.21273/HORTTECH.17.1.67

Zighelboim, M. S. (2015). Method and apparatus for marking coconuts and similar food products. U.S. Patent No. 0030731A1. 


\section{APPENDIX}

Velocity: The marking speed (X-Y optical scanner speed) of the object. It determines how fast the galvanometer moves and how fast each microvector is marked.

Resolution: The minimum galvanometer step distance or microvector. This affects how the markings appear. A small resolution shortens the marking time but results in poor marking of the object, while a bigger resolution delays the marking time but results in better marking of the object.

Pline start delay: The delay at the beginning of a polyline (or series of polylines) that compensates for the time difference between the laser firing and the actual movement of the mirror. It reduces hotspots (dwells) at the beginning of a polyline or a series of polylines.

Pline end delay: The time delay between the target and the actual mirror position at the end of a polyline (or series of polylines). It ensures that a polyline is completed before moving unto the next one by maintaining the right beam at the end of a polyline or series of polylines.

Interseg delay: The time delay between the target and the actual mirror position of two connecting on-vectors. It connects polylines when the end point of one polyline is the start of the next polyline in the object by setting a delay between them. The sharpness of the points where the polylines are connected is increased by Interseg Delay.

Off vector delay: The time delay between the target and the actual mirror position of an off-vector connecting to an on-vector. It is used to set a proportional delay to remove "tails" i.e., extension of polylines when moving between non-connected polylines during all laser off-vector moves.

Bi-directional raster: Shows if the scanlines will be marked in both directions (top/bottom, left/right) when marking a raster fill or bitmap. It can increase the marking speed when enabled.

Interseg break angle: The break angle between two connected polylines. If the angle between the polylines is greater than break angle, Interseg Delay is used. However, when the angle between two marked polylines is less than the specified angle, Interseg Break Angle is not used.

Off vector velocity: The velocity at which the galvanometer moves between line segments.

Off vector resolution: The resolution used when making laser-off moves in dots per inch.

Raster scan direction: Shows the direction in which the markings should be done whether horizontally or vertically. 